\title{
TECHNOLOGICAL ASPECTS REGARDING THE MANUFACTURE OF SCREW-RETAINED PROSTHETIC RESTORATIONS MADE OF CERAMIC MASSES ON ZIRCONIA STRUCTURE (PART II)
}

\author{
RADU COSTEA ${ }^{1}$, CLAUDIA CAMELIA BURCEA ${ }^{2}$, NICOLETA MĂRU ${ }^{3}$, VIOREL ȘTEFAN PERIEANU ${ }^{4}$, \\ MIRELA VERONICA BUCUR ${ }^{5}$, MIHAI BURLIBAȘA ${ }^{6}$, STEFAN MILICESCU ${ }^{7}$, MẲDĂLINA VIOLETA \\ PERIEANU $^{8}$, MĂDĂLINA ADRIANA MALIȚA ${ }^{9}$, IRINÁ ADRIANA BEURAN ${ }^{10}$, IULIANA BABIUC ${ }^{11}$, \\ NARCIS MARCOV ${ }^{12}$, ELENA-CRISTINA MARCOV ${ }^{13}$, SERGIU DRAFTA $^{14}$ \\ 1,2,3,4,5,6,7,8,9,10,11,12,13,14 “Carol Davila” University of Medicine and Pharmacy Bucharest,
}

\begin{abstract}
Keywords: implant- Abstract: With the help of dental implants, an oral rehabilitation can be performed not only very prosthetic rehabilitation, complex, but also very complete of various types of edentulous spaces. After insertion of the dental screw-retained prosthetic implants, they can be subsequently prosthetically restored through a wide range of implant-supported restorations, Zirconia, prosthetic restorations. In this material, we tried to highlight some particular aspects from the point ceramic masses of view of the laboratory stages of dental technique, which intervene in the technological flow of making implant-supported prosthetic restorations from ceramic masses on Zirconia structure.
\end{abstract}

\section{INTRODUCTION}

As mentioned in the first part of this material, published in a previous issue of the Acta Medica Transilvanica Journal, oral implantology has known new methods and has made significant progress, by developing technologies and new materials, which have had as a result of both aesthetic and functional improvement.(1-5)

Thus, with the help of dental implants, a complex and complete oral rehabilitation of various types of edentulous spaces can be performed, the inserted oral implants being subsequently used for a wide range of implant-supported prosthetic restorations fixed and/or mobile.

\section{AIM}

Oral rehabilitation of edentulous alveolar ridges with dental implants, includes 2 distinct stages: a stage with surgical profile of intraosseous insertion of the dental implant and a prosthetic stage, having a double composition - clinical (in dental office) and technical (in laboratory of dental technique). Specifically, this oral rehabilitation of edentulous alveolar ridges with the help of dental implants, for a simple communication, has been called in the literature using the term "implantprosthetic rehabilitation", a term that, in this context defines high precision both in the surgical stage of insertion of oral implants and, subsequently, in the prosthetic stage.(1-7)

In fact, in this second part of the material, we will try to present a series of peculiarities of the technology for making implant-supported screw-retained prosthetic restorations made of ceramic masses on the structure of Zirconia, as we mentioned in the first part of the material, which is in fact the purpose of this study.

\section{MATERIALS AND METHODS}

The dental implant is a medical device made of titanium, titanium alloys or zirconia. This device is shaped like a screw, has variable dimensions, and is inserted into the maxillary or mandibular bone after a rather laborious surgery, in order to replace one or more teeth, which were lost as a result of extractions or other dental complications.

A quality implant supported prosthetic restoration has the following components:(1-14)

- The implant itself - corresponds to the root of the tooth and comes in several shapes, lengths and diameters.

- Prosthetic abutment - is the connecting element between the implant body and the dental crown.

- Fixing screw - is the connecting element between the implant itself and the elements that are attached to it.

- Dental crown - is the visible part in the oral cavity, made by the dental technician and adapted by the prosthetic specialist.

Among the materials used for creating the infrastructure of implant-supported prosthetic restorations, including the modern CAD-CAM method, special mention must be made of Zirconium Dioxide - Zirconia.

Zirconium oxide $\left(\mathrm{ZrO}_{2}\right)$ is a ceramic material existing in different phases, depending on temperature. This material was discovered in 1789 by the German chemist M.H. Klaproth and was originally used for industrial purposes. With the evolution of CAD / CAM technology, Zirconia was introduced in dentistry, having a great contribution in dental prosthetics (construction of mixed crown infrastructure, dental bridges, veneers), in implant-prosthetic rehabilitation (making implants and abutments, prosthetic restorations etc.), but also in orthodontics.(1-14)

Zirconium is a chemical element in the group of metals, which has atomic number 40 . The chemical symbol is Zr. Zirconium dioxide or zirconia is a white material with a crystalline structure. It is obtained from the mineral called zircon, a very hard compound of the $\mathrm{ZrSiO}_{4}$ silicate class, often used as a semi-precious stone. Zirconia has been used in

${ }^{4}$ Corresponding author: Viorel Ștefan Perieanu, Str. Plevnei, Nr. 19, Sector 1, București, România, E-mail: mburlibasa@gmail.com, Phone: +40723 472632

Article received on 29.10.2021 and accepted for publication on 02.12.2021 


\section{CLINICAL ASPECTS}

dentistry since the 1990s.(1-14)

\section{RESULTS AND DISCUSSIONS}

\section{Clinical case presentation}

Patient WW presented to the dentist's office, in order to restore the first and second upper left premolars, lost due to severe coronary damage. After performing the clinical and radiological exam, the dentist established the treatment plan, which consisted in restoring of the two premolars with the help of a screwed-retained implant-supported ceramic bridge on the structure of Zirconia.

Following the performance of characteristic medical investigations and choosing dental implants, the dentist performed the surgical operation. The healing abutment were attached to dental implants. This stage was followed by a waiting period of 6 months for the osseointegration of dental implants.

Subsequently, the preliminary maxillary impression with irreversible hydrocolloid (alginate) was taken in a standard impression tray, after which the study cast was made in the dental laboratory. The study cast was made of type 4 dental stone, using the vacuum mixer and the vibrating table. An open impression tray was made on the study cast.

The maxillary functional impression was taken by the dentist with a polyether (Impregum) in the individual spoon tray, with the transfer abutments fixed on the dental implants. After the setting of the impression material, the transfer abutments were unscrewed, remaining fixed in the impression. The functional impression of the mandible was taken with silicone material of putty and light body consistency in a standard impression tray. The occlusion was recorded with siliconic material of putty consistency.

In the dental laboratory, the impressions were washed and disinfected. In the impression, next to the dental implants, elastic Gingifast material was applied. To the transfer abutments, implant analog abutments were fixed. The functional models were cast using the vacuum mixer and the vibrating table, with type four dental stone.

The maxillary sectional model was made using the Accu-Trac technique, and the model of antagonistic teeth (mandibular) was made by the Giroform technique. The models were mounted in the Amann Girrbach articulator, respecting the occlusal registration.

\section{Figure no. 1. Models mounted in the articulator}

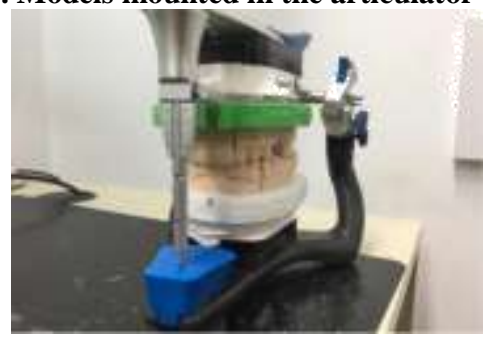

Straumann prosthetic abutments were individualized and anti-rotational systems were developed.

Figure no. 2. Models mounted in the articulator lateral view

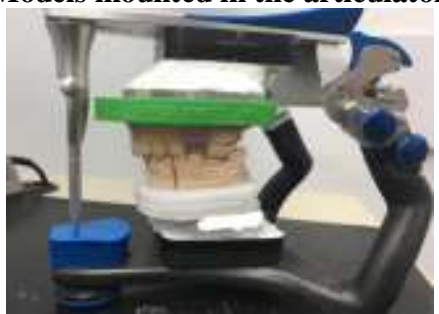

Prior to scanning the models, the prosthetic abutments were covered with powder scan spray sprayed in order not to reflect the light.

\section{Figure no. 3. Models before scanning}

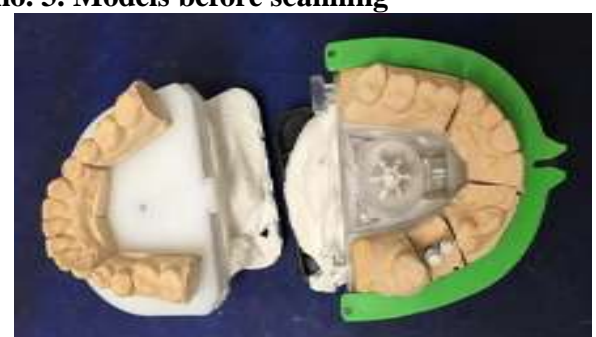

The models were scanned for CAD-CAM, using the Ceramill Mind software.

Figure no. 4. Treatment plan

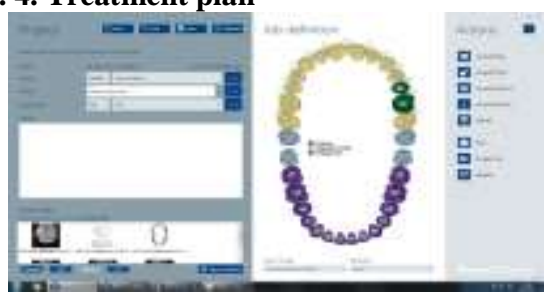

When designing, physiognomic crowns were chosen from the CAD-CAM library, from which the volume was reduced, reaching the size of the future coping.

\section{Figure no. 5. Design of physiognomic crowns}

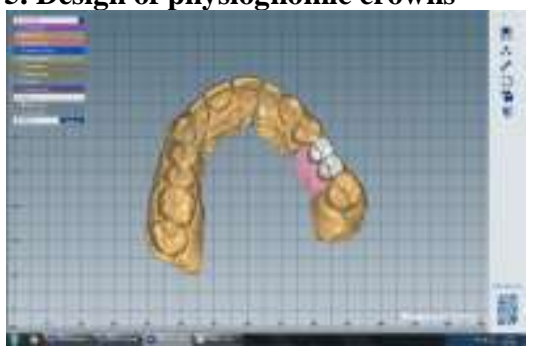

Figure no. 6. Coping design

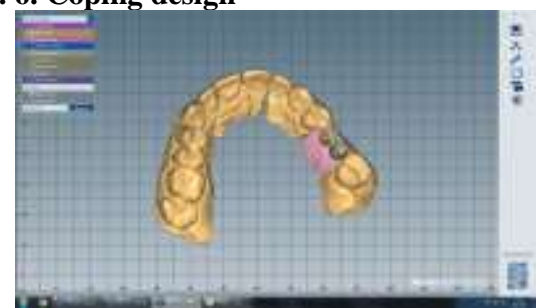

In the virtual articulator, the laterality and propulsive movements were performed, in order to verify and correct the functionality of the future prosthetic work and to ensure that there is sufficient occlusal, vestibular, palatal and proximal space for the stratification of the ceramics.

Figure no. 7. Models placed in the virtual articulator

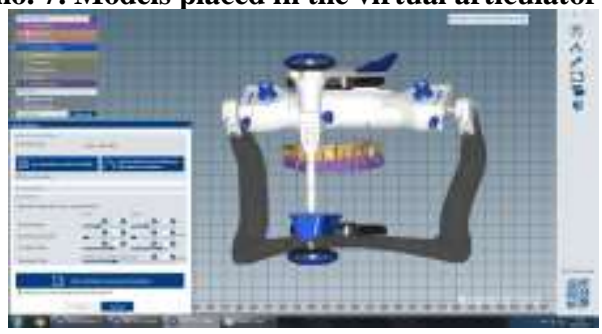




\section{CLINICAL ASPECTS}

The Zirconia bridge was CAD-CAM milled.

Figure no. 8. Solidified capes milled in the zirconia disc

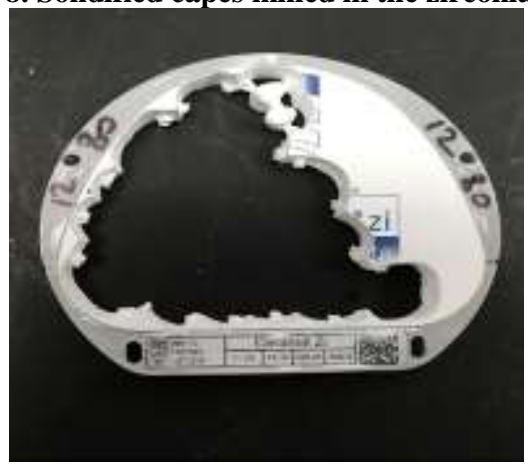

Figure no. 9. Dyeing of zirconium oxide before sintering

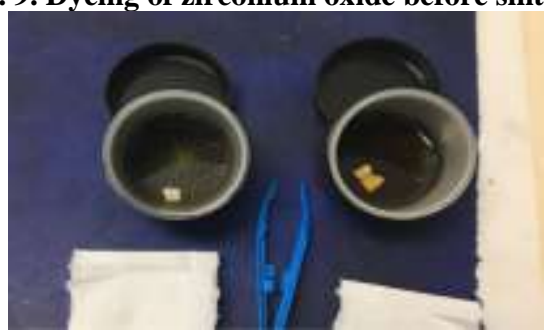

Figure no. 10. Zirconia coping adapted on the model

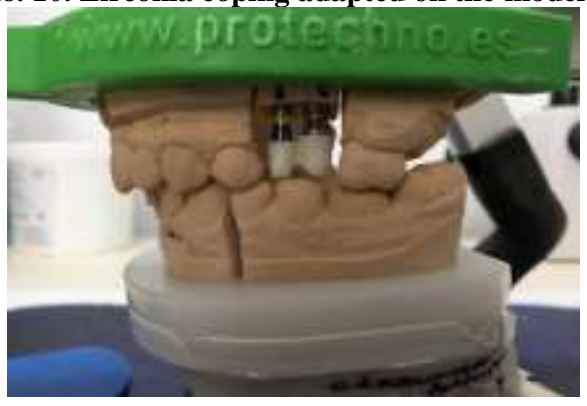

Figure no. 11. Zirconia structure occlusal view

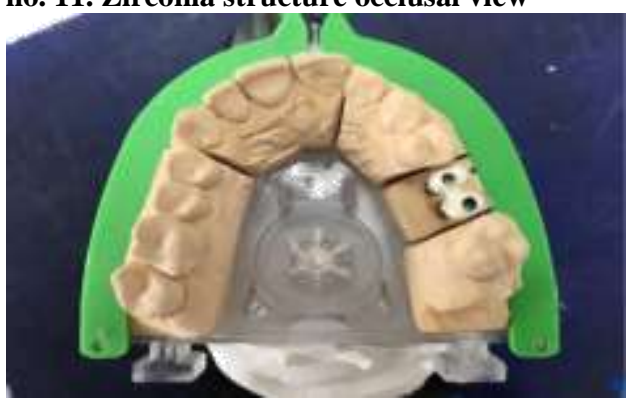

After applying and firing the wash, dentin and enamel Ivoclar E-max ceramic was layered.

Figure no. 12. Laminated ceramic before firing

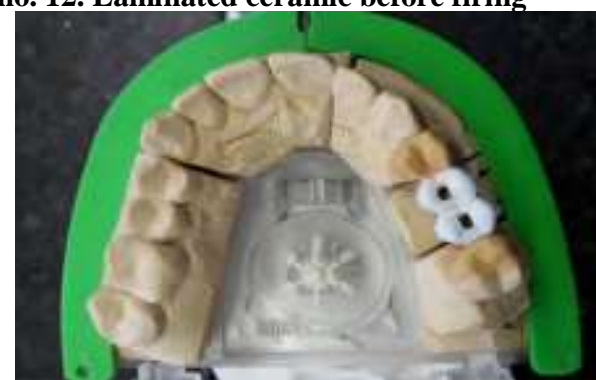

Figure no. 13. Ceramic before firing lateral view

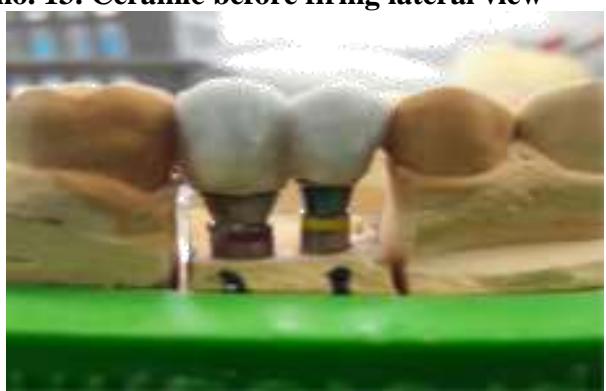

The ceramic was fired using the appropriate firing cycle. After firing, the ceramic was adjusted in occlusion.

Figure no. 14. Adaptation in occlusion

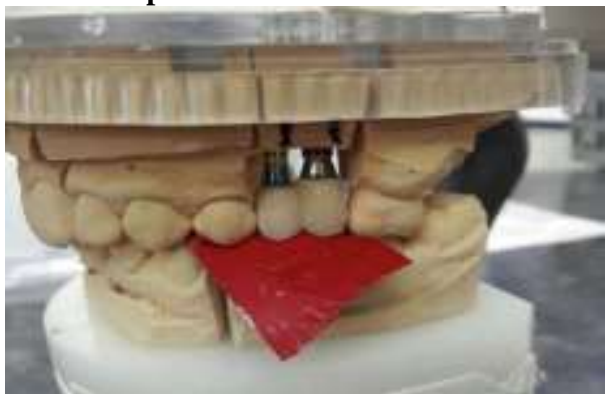

After processing, the glaze was applied and fired in the ceramic oven.

Figure no. 15. a, b Ceramic prosthetic restoration on Zirconia infrastructure in final stage
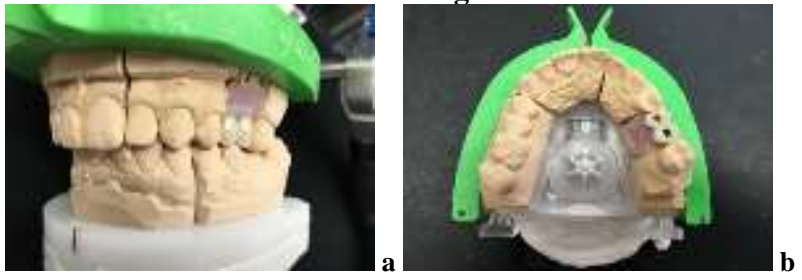

Creating a screw-retained implant-supported prosthetic restoration can be achieved only through a succession of clinical-technical stages, which is carried out through a very efficient professional collaboration between the dentist and the dental technician. The clinical stages are performed in the dental office, and the technical ones in the dental laboratory.

The success of implant-prosthetic rehabilitation therapy belongs equally to the staff working in the clinical department, the dental office - the dentist, and to the qualified staff working in the dental laboratory - the dental technician. However, the responsibility lies exclusively with the dentist, who leads the medical team and decides on the treatment plan, but also the therapeutic solution.

\section{CONCLUSIONS}

The increasingly frequent use of zirconia for implantsupported prosthetic restorations is favoured by several aspects such as:

- Zirconia is a perfectly biocompatible material, so it does not cause any allergies.

- Zirconia has a very low affinity for bacterial plaque, poor hygiene being one of the causes of failure and loss of dental implants.

- It is the only material from which bridges are currently made without a metal structure.

- The aesthetics of the dental work is special, as the restored teeth have a natural look. 


\section{CLINICAL ASPECTS}

- The special resistance to pressure makes it able to withstand masticatory stresses and daily wear and tear, without fracturing.

- The possibility of making a mixed crown, without metal support, is a sign of the evolution in dentistry. In order to obtain aesthetic results superior to the porcelain fused to metal crown, the zirconia substructure is used.

- The use of zirconia makes the adaptation of crowns or bridges perfect. Due to non-use of metal reinforcement (which the dental technician must mask with an ceramic opaque layer), made it possible to make crowns with reduced thickness, thus reducing the sacrifice of healthy dental tissue during the preparation of teeth.

- The aesthetic results are excellent due to the fact that the light is no longer interrupted by the underlying metal, and therefore can cross the crown and can restore the natural appearance of the tooth.

We can appreciate the fact that the fixed implantsupported prosthetic restorations with zirconia infrastructure are lighter than the ones on metal support, so the accommodation with the new prosthetic works is much faster. This is very important, especially in the case of dental bridges with a large number of elements. The precision of the work is guaranteed by the realization of the internal structure by the computer, by creating the design of the dental work and milling in a solid block of zirconium oxide.

Acknowledgement:

In this article, all the authors have equal contribution with the first author.

\section{REFERENCES}

1. Costea R, Perieanu MV, Dina NM, Burlibasa M, Beuran IA, Bodnar DC, Milicescu S, Maru N, Tanase G, Marcov EC, Babiuc I, Butucescu M, Moraru L. Technological aspects regarding the manufacture of screw-retained prosthetic restorations made of ceramic masses on Zirconia structure (Part I). Acta Medica Transilvanica. 2021;26(3):71-74.

2. Cristache CM, Burlibasa M, Cristache G, Drafta S, Popovici IA, Iliescu AA, Zisi S, Burlibasa L, Zirconia and its biomedical applications, Metalurgia International vol XVI (2011), no. 7, ISSN 1582-2214 p. 18-23(IF 0,134).

3. Mocuța D, Popovici IA, Burlibasa L, Cristache G, Sfeatcu $\mathrm{R}$, Bodnar $\mathrm{T}$. Impact of the living conditions on population health. Metalurgia International. 2009;14:17-19.

4. Burlibasa L, Chifiriuc MC, Lungu MV, Lungulescu EM, Mitrea S, Sbarcea G, Popa M, Marutescu L, Constantin N, Bleotu C, Hermenean A. Sythesis, physico-chemical characterization, antimicrobial activity and toxicological featurs of $\mathrm{Ag}-\mathrm{ZnO}$ nanoparticles, Arabian Journal of Chemistry. 2020;13(1):4180-4197.

5. Burlibașa M, Cernușcă-Mițariu M, Cernușcă-Mițariu S, Mițariu M, Malița M. Theoretical and practical aspects related to biomaterials decontamination in dental medicine (with reference to dental prosthetics). Metalurgia International. 2013; Vol. XVIII, No. 4, p. 261-267.

6. Mocuta D, Popovici LR, Dumitriu AS, Burlibașa L, Ionescu CA, Sfeatcu R. Life quality-condition of social welfare. Metalurgia International. 2009;14:62-64.

7. Burlibașa M, Muntianu L, Tănase G, Bucur MB, Comes $\mathrm{CA}$, Ionescu CA. Study on microbial contamination of biomaterials in medical practice. Metalurgia International. 2010; Vol. XV, Spec. Issue No. 2, p. 163-166.

8. Ispas DC, Eftene OA, Burlibaşa M, Bucur MB, Tănase G, Cristache CM. Implications of titanium in orthodontics and dental facial orthopedics. Metalurgia International. 2011; Vol. XVI, Isuue No. 10, p. 72-74.

AMT, vol. 26, no. 4, 2021, p. 82
9. Tănase G, Burlibașa M, Muntianu L, Simion I, Bucur MB, Ionescu CA. Testing the antibacterial potential of biomaterials in medical practice. Metalurgia International. 2010; Vol. XV, Spec. Issue No. 2, p. 160-162.

10. Burlibașa M, Tănase G, Muntianu L, Murgu AI, Teodorescu E, Malița C. Quality of life, a multidisciplinary concept with economic and social impacts in medical practice. Metalurgia International. 2010; Vol. XV, Spec. Issue No. 4, p. 88-90.

11. Burlibașa M, Cernușcă-Mițariu M, Burcea CC, Mițariu M, Ferechide D. Halogen compounds - theoretical, physiological and practical aspects regarding the decontamination, disinfection and sterilisation of instruments and biomaterials in dental medicine practice. Metalurgia International. 2012; Vol. XVIII, Spec. Issue No. 3, p. 54-57.

12. Eșian D, Man A, Burlibașa L, Burlibașa M, Perieanu MV, Bică C. Salivary level of Streptococcus mutans and Lactobacillus spp. related to a high risk of caries disease. Rom Biotechnol Lett. 2017; Vol. 22, No. 2, p. 1249612503.

13. Eftimie Totu E, Cristache CM, Isildak I, Yldirim R, Burlibasa M, Nigde M, Burlibasa L. Citotoxicity and genotoxicity assessment of the PMMA-TiO2 nanocompozites for stereolithographic complete dentures manufacturing. Revista de Chimie. 2018; Vol. 69, No. 5, p.1160-1165.

14. Petrescu L, Petrescu C, Mitrut O, Moise G, Moldoveanu A, Moldoveanu F, Leordeanu M. Integrating biosignals measurement in virtual reality environments for anxiety detection. Sensors. 2020;20(24):7088. 